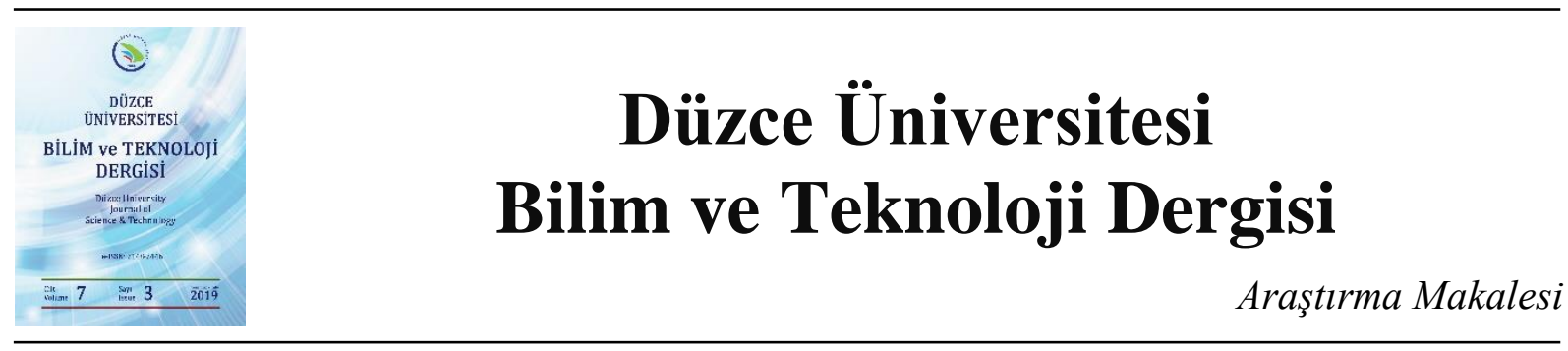

\section{P300 Tabanlı Beyin Bilgisayar Arayüzü Sistemlerinde Uyaranlar Arası Sürenin ve Uyaran Yapısının Performansa Etkisi}

\author{
(iD) Zeki ORALHAN ${ }^{\mathrm{a}, *}$ \\ ${ }^{a}$ Elektrik Elektronik Mühendisliği Bölümü, Mühendislik Fakültesi, Nuh Naci Yazgan Üniversitesi, Kayseri, \\ TÜRKIYE \\ * Sorumlu yazarin e-posta adresi: zoralhan@nny.edu.tr \\ DOI : $10.29130 /$ dubited.562610
}

\begin{abstract}
ÖZET
Elektroensefalografi temelli beyin bilgisayar arayüzü sistemleri kas sistemini kullanamayan hastalar için dış dünya ile iletişimini mümkün kılmaktadır. EEG temelli beyin bilgisayar arayüzü sistemleri için çeşitli beyin sinyal aktiviteleri kullanılmaktadır. Olay odaklı potansiyellerden bir tanesi olan P300 sinyali beyin bilgisayar arayüzü sistemleri için elverişli bir beyin sinyalidir. P300 tabanlı bir beyin bilgsayar arayüzü için en önemli performans parametrelerinden birisi sınıflandırma doğruluk oranıdır. Bu çalışmada satır sütun temelli P300 heceletici yapısındaki değişiklikle daha yüksek doğruluk oranı ile elde edilmesi hedeflenmiştir. P300 heceleticisi matris yapısında ve uyaranların aralık süreleri üzerinde değişiklikler yapılmıştır. Bundan önceki bir çok çalışma P300 heceletici yapısındaki uyaran renk ve biçimlerindeki değişiklikler ile yapılmışıır. Uyaran yapısı ve uyaran aralık sürelerindeki değiş̧ikleri kıyaslayıcı P300 heceleticileri ile ilgili çalışmalar yeterli seviyede değildir. Bu çalışmada dört farklı yapıdaki satır sütun bazlı P300 heceletici kullanılarak deneyler yapılmıştır. Deneyler ile toplanan EEG kayıtları ön işlemden geçirildikten sonra adımsal doğrusal ayrışım analizi ile sınıflandırılmış̧ır. Sınıflandırma neticesinde bu çalışmada karşılaştırılan heceleticilerden; 4x4 satır sütın bazlı P300 heceleticinin 150 ms uyaran aralık süresine sahip olan yapıdaki formu, ortalama doğruluk oranı \%84,76 ile en yüksek olarak tespit edilmiştir. En düşük performans ise; 6x6 satır sütın bazlı P300 heceleticinin 300 ms uyaranlar arası geçiş süresine sahip modunda \%50,48 olarak gözlenmiştir. Bu çalışma, satır sütun bazlı P300 heceleticisinin uyaran matris yapısındaki değişikliği ve farklı uyaran aralık sürelerinde yapılan deneylerle yüksek doğruluk oranı ile elde edilebileceğini göstermiştir.
\end{abstract}

Anahtar Kelimeler: EEG, P300, Beyin Bilgisayar Arayüzü (BBA)

\section{The Effects of Stimulus Structure and Inter Stimulus Interval in P300 based Brain Computer Interface Systems}

\begin{abstract}
$\underline{\text { ABSTRACT }}$
Electroencephalography based brain computer interface systems provide communication with the environmental devices for users who cannot use neuromuscular system. There are various brain signal activities for EEG-based
\end{abstract}


BCIs. P300 is a type of event related potential and is a convenient signal type for BCI systems. One of the most important performance parameters is the classification accuracy rate for a P300-based BCI. In this study we aimed to obtain a higher accuracy rate with the changes of row column based P300 speller structure. Changes were made to the matrix structure of P300 speller and inter stimulus interval duration. our new approach region based P300 speller. In most of previous studies are about changes of stimlus color and shapes in row column based P300 speller. In this research experiments with 4 different modes P300 speller were used for character selection. The EEG recordings that collected in the experiments were pre-processed and then classified by stepwise linear discriminant analysis. Acording to the classification result the highest average of the classification accuracy was reached to $84.76 \%$ in the experiments with $4 \times 4$ matrix based P300 speller with $150 \mathrm{~ms}$ inter stimulus interval duration. In the contrary of this the lowest classification accuracy was observed with 6x6 matrix based P300 speller with $300 \mathrm{~ms}$ inter stimulus interval duration. This study showed that the row column based P300 speller can be achieved to high accuracy rate with changes in stimulus matrix structure and inter stimulus interval duration.

Keywords: EEG, P300, Brain Computer Interface (BCI)

\section{$\underline{\text { I. GiRis }}$}

$\mathrm{B}$ eyin bilgisayar arayüzü (BBA) sistemleri kullanıcıların elektronik bir sisteme ya da bilgisayara periferik motor sistemlerini kullanmadan komut ya da mesaj göndermelerine olanak sağlar. BBA'lar beyinsel aktiviteleri kullanarak gerçekleştirilirler [1]. Beyin aktivitelerinin ölçüm yöntemlerine göre çeşitli BBA'lar mevcuttur. Bu ölçüm yöntemleri arasında; fonksiyonel manyetik rezonans, yakın kızı ötesi spektroskopisi, manyetoensefalografi ve elektroensefalografi (EEG) bulunmaktadır. BBA'lar için en çok kullanılan yöntem beyindeki sinir grubunun oluşturduğu elektriksel aktivitenin kafa derisinden elektrotlarla ölçümüne dayalı EEG yöntemidir [2-3]. EEG’ler girişimsel olmayan, gerçek zamanlı veriler alınarak işlenmesini sağlayan, sinyal cevapları yüksek olmasından dolayı BBA sistemlerinde tercih edilmektedirler.

EEG tabanlı BBA'larda ise; durgun durağan görsel uyaran potansiyelleri, P300 sinyali, motor nöron sinyalleri, yavaş kortikal potansiyel aktiviteleri kullanılmaktadır [4-5]. En çok kullanılan yöntemlerden birisi ise P300 sinyalini kullanarak komutların verilmesidir. P300 tabanlı BBA sistemleri, pratik, hızlı oluşu ve bilişsel yorgunluk yapamamasından dolayı tercih edilmektedir. P300 bir beklenti sinyali olarakta değerlendirilebilir [6]. Sutton ve arkadaşları 1965 yılında P300 dalgalarını keşfetmişlerdir. Uyarandan beklenen bilgi geldiğinde, içsel bir tepki olarak beyinden genellikle $250 \mathrm{~ms}-450 \mathrm{~ms}$ sonrasında pozitif yönlü EEG sinyalinde dalgalanma olur. Sinyalin pik noktası $300 \mathrm{~ms}$ civarında olduğu için P300 ya da P3 adı ile anılır ve olay odaklı sinyaller içersinde net gözlemlenebilen en önemli sinyallerden birisidir [7]. Bu gecikme sürelerinin değeri bir olaydan başka bir olaya geçişteki sınıflandırma hızına bağlır. Gecikme sürelerinin kısalması daha iyi bir mental performansın sonucudur. Çeşitli paradigmalar P300 sinyalinin oluşumu için kullanmakta olup bunların en yaygın olan Oddball paradigmasıdır. Bu paradigmada farklı uyaranlar sunulurken beklenen uyarı daha seyrek olarak sunulmaktadır. Beklenen uyarana beynin vereceği cevap P300 sinyalidir. Bu beklenti sinyali beynin tepe bölgelerinde daha belirgin bir şekilde elde edilmektedir [8-11].

Şekil 1'deki şemada P300 tabanlı BBA sistemlerinin yapısı gösterilmiştir. Bu yapıda genellikle 2 aşamada sistem gerçekleştirilir. 1. aşamada kullanıcıya önceden verilen görev gerçekleştirilerek sistem 
eğitilmektedir. Kullanıcıya göre eğitilen sistemde 2.aşamada görev verilmeden istenilen komutun verilmesi gerçekleştirilir.

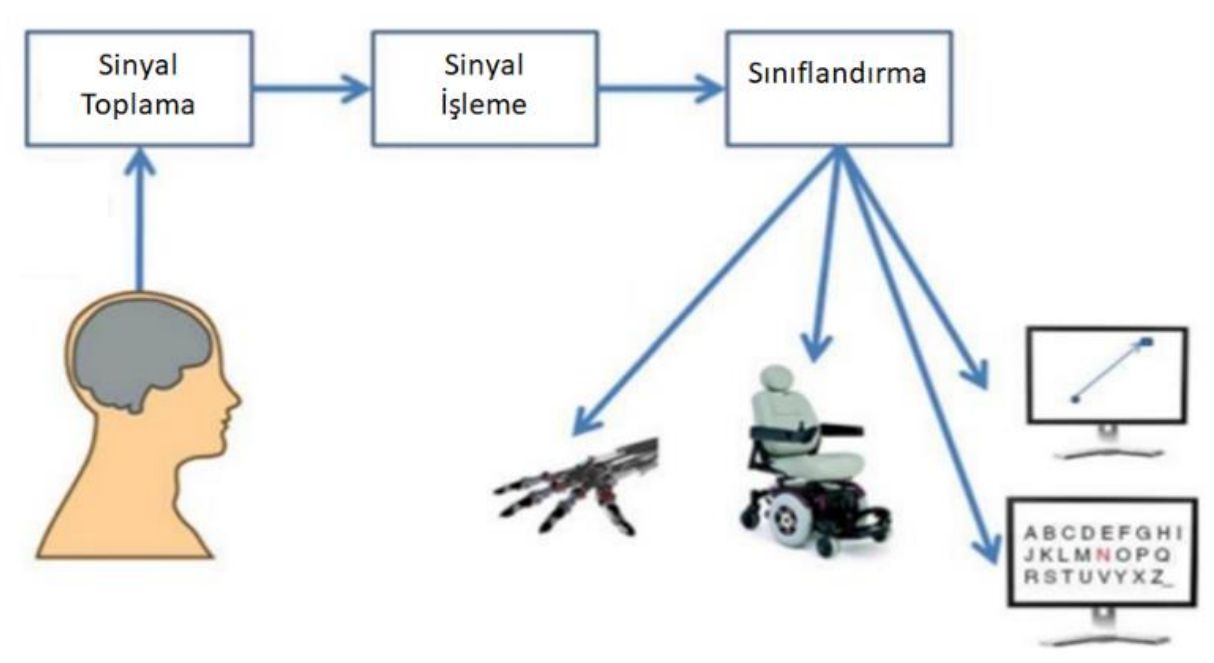

Şekil 1. P300 Tabanlı Beyin Bilgisayar Arayüzü Sistemi Şeması

Guger ve arkadaşları 2009 yılında satır-sütun uyaran odaklı mekanizmayı motor hayali görüntü ve P300 tabanlı BBA sistemlerinde kullanmıştır. Katılımcıların doğruluk oranı yüksekliği P300 tabanlı BBA sisteminde önemli derecede daha fazla olduğunu göstermişlerdir [13]. Salvaris ve sepulveda satır sütun P300 heceletisi üzerinde uyaran rengi, zemin rengi, karakter boyutu, yazı tipi gibi özellikleri değiştirerek türev P300 heceleticilerinin performanslarını incelemiştir. Siyah zemin beyaz karakter protokolündeki heceleticide en yüksek performansı, küçük boyutlu karakterlerde de en düşük performansı elde etmişlerdir [15]. Townsend ve arkadaşları dama tahtası şekli üzerine karakterleri yerleştirerek oluşturdukları P300 heceleticisinden en yüksek performansı elde etmelerine karşıı görsel karışıklık ve yüksek matris boyutundan dolayı odaklanmayı zorlaştırmıştır [16].

Diğer P300 heceleticisi olarak sadece ilgili karakterin yanıp sönmesi olarak tasarlanmış P300 tabanlı BBA sistemi mevcut olup, performansı satır sutün heceleticisine sahip BBA'lara göre düşüktür.

Ayrıca P300 tabanlı BBA sistemleri işitsel uyaranlarla da tasarlanabilir. Amyotrofik lateral skleroz (ALS) hastaları ilerleyen dönemlerde locked-in syndrome (LIS) evresinde yatay göz hareketlerini gerçekleştiremezler. Bununla birlikte çeşitli nörodejeneratif hastalıklarda hastalar göz kaslarını kontrol edemezler [18-19]. Bundan dolayı oddball paradigramasına dayanarak işitsel P300 tabanlı BBA sistemlerinde tasarlanabilmektedir [20]. Kübler ve arkadaşlarının ALS hastalarının LIS evresindekiler için geliştirdikleri P300 tabanlı BBA sisteminde 5X5 matris ile her satır ve sütunda 1'den 10'a kadar satır ve sütunları kodlamışlardır. Bir erkek sesi tarafından karışık biçimde harfler söylenmektedir. Kullanıcı yazdırmak istediği karakterin satır veya sütunundaki rakamın okunuşuna odaklanmaktır [21]. Belitski ve arkadaşları işitsel ve görsel uyaranların birlikte kullanıldığı bir BBA sistem tasarımında, klasik satır sütun P300 görsel uyaran heceleticisine göre daha iyi performans elde etmişlerdir.

\section{II. İlgilì ÇALIȘMalar Ve Mevcut ÇALișma}


Bu çalışmada araştırılan satır sütun temelli P300 heceleticisi özelliklerine benzer çalışmalarda literatüre yeni bulgular kazandırmıştır. 1988 yılında Farwell ve Donchin ilk defa P300 tabanlı gerçek zamanlı BBA sistemi gerçekleştirilmiştir. 6x6 'lk matris şeklinde hazırladıkları 36 karakterli görsel uyaranlar 6'lı satır ve sütunlar halinde rastgele yanıp sönmektedir. Kullanıcının odaklandığı karakter yandığında beyninden $300 \mathrm{~ms}$ sonrasinda meydana gelen P300 beklenti sinyalini elde ederek BBA sistemini geliştirmişlerdir [12]. Farwell ve Donchin çalışmalarında uzun süreli uyaran aralıklarında, daha yüksek doğruluk oranına ulaşırken, bunun aksi olarak, Meinicke ve arkadaşları 2002 yılında yaptıkları araştırma neticesinde kısa süreli uyaran aralıklarında daha yüksek doğruluk oranına erişmişlerdir [17]. Ayrıca, Allison ve Pineda 3 farklı matris yapısında P300 heceleticisi kullanmışlardır. 4X4, 8X8 ve 12X12 matris boyutlarında P300 heceleticisi ile yaptıkları deneyde; matris boyutu arttıkça, P300 potansiyel genliğinin arttığını gözlemlemişlerdir [22]. Ancak sınıflandırma doğruluk oranı üzerine bir raporlama yapmamışlardır. Satır sutün P300 heceleticisindeki matris boyutları üzerinde Sellers ve arkadaşları yaptıkları çalışmada 6X6'lık P300 heceleticide elde edilen sınıflandırma doğruluk oranını 3X3'lük heceleticede elde edilene göre daha yüksek bulmuşlardır [14].

Çalışmalar, uyaran aralıkları arasındaki sürenin P300 heceleticisi üzerindeki sınıflandırma doğruluk oranı üzerinde etkilerini farklı olarak göstermiştir. Bu çalışmada satır sütün matris bazlı görsel uyaranlarla oluşturan P300 heceleticisi geliştirilmiş. Geliştirilen bu yeni yapıdaki P300 heceleticisinde uyaranlar arası sürenin BBA sisteminin performansına etkileri incelenmiştir.

\section{METOT}

$\mathrm{Bu}$ çalışmada görsel uyarana sahip satır sütun bazlı P300 heceleticisi hazırlanmıştır. Geliştirilen 6x6 matris ve $4 \times 4$ matris (satır sütun) tabanlı P300 heceletisinde uyaranların flaş yapma aralıklarındaki farklı süreler kullanılarak deneyler gerçekleştirilmiştir. Uyaranlar arası flaş yapma geçiş sürelerinin ve uyaran sayısının P300 tabanlı BBA sistem performansına etkileri incelenmiştir.

\section{A. DENEY KATILIMCILARI}

Bu çalışma kapsamında deneylere 7 sağlıklı birey katılım sağlamıştır. Katılımcılar erkek olup ortalama yaşları $27 \pm 3^{\prime}$ dür. Bireyler normal işitme ve görme yetilerine sahip ve geçmişinde de bir psikiyatrik rahatsızlık geçirmemişlerdir.

\section{B. P300 HECELETICI YAPISI}

Geliştirilen P300 heceleticisinde ayarlar menüsünden satır ve sütun sayısını, hangi karakterlerin gösterilmesini ve uyaranların flaş yapma geçiş süreleri ayarlanabiliyor. Şekil 2'de 6x6 satır sütun matris tabanlı P300 heceletisi bu çalışmada hazırlanmış olan heceleticinin ekran görüntüsü olup her bir satır ve sütun rastgele olarak koyu giriden beyaz renge geçiş (flaş) yapmaktadır. $4 \times 4$ satır sütun matris yapısı da şekil 3'te gösterildiği üzere sayılar ve Türkçe karakterlerden oluşmaktadır. Kullanıcıdan ekranda yazdırmak istediği karakterin bulunduğu satır veya sütun flaş yaptığında sayması istenmiştir. Oddball paradigmasına dayanarak, kullanıcı hedeflediği karakterin bulunduğu her bir satır ve sütun yanınca pozitif yönlü beklenti sinyali oluşmaktadır. BBA sistemi sinyal işleme işlemleri ve sinyal sınıflandırma adımıyla hangi satır ve sütunda P300 sinyalinin oluştuğunu tespit edecektir. Hedeflenen karakter satır 
ve sütunun çapraz olarak kesiştiği uyaran olarak bulunur. Bu geliştirilen P300 heceleticisi arayüzü C\# progralama dili ile Microsoft Visual Studio 12.0 ortamında geliştirilmiştir.

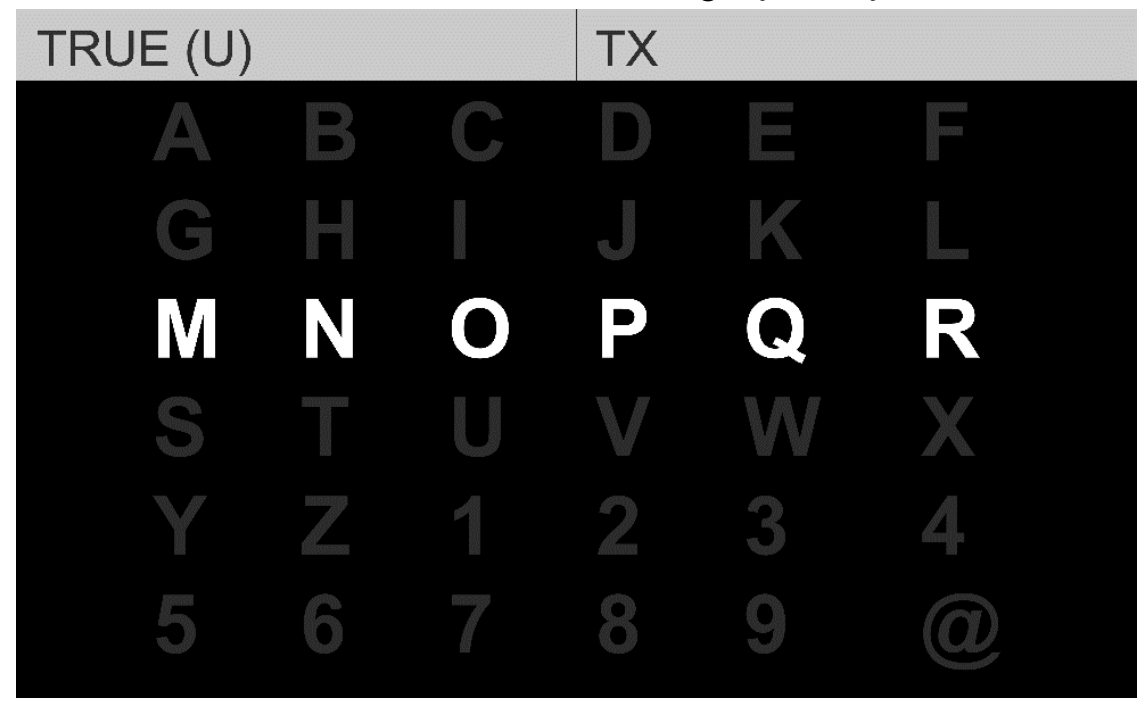

Şekil 2. 6x6 Satır Sütun Bazlı P300 Heceletici

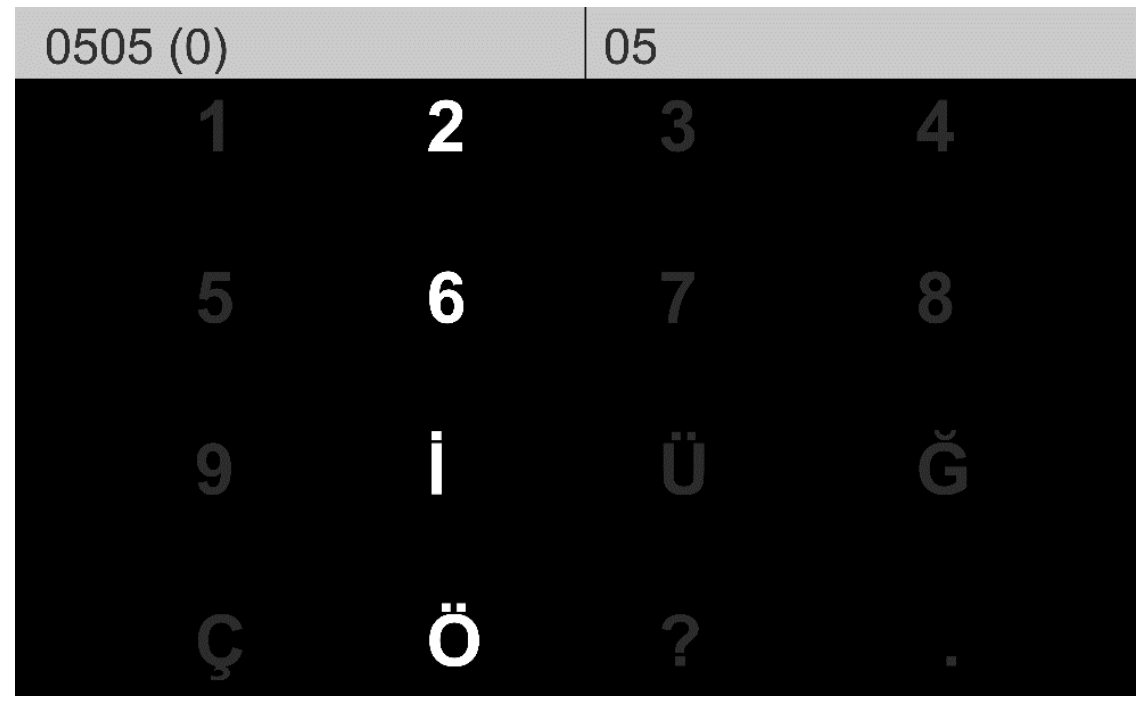

Şekil 3. 4x4 Satır Sütun Bazlı P300 Heceletici

\section{EEG SINYALININ TOPLANMASI}

EEG sinyalleri saçlı deriden girişimsel olmayan yöntemle CleveMed BioRadio cihazından 7 adet altın kaplama elektrot ile kayıt altına alındı. Elektrotlar saçlı deriye uluslararası 10-20 sistemine göre yerleştirilmiştir. Referans elektrot sol kulak ucuna yerleştirilmitir. Kayıtlar ses geçirmeyen bir odada alınmıştır. EEG kayıtları $500 \mathrm{~Hz}$ frekansında örneklemiştir.

D. DENEY PROSEDÜR 
Deney kullanıcının baş hizasından 60 cm uzağına yerleştirilen 1366x768 pixel çözünürlüğündeki liquid crystal display (LCD) monitordeki, bu çalışmaya özgü hazırlanan P300 heceleticisi ile gerçekleştirilmiştir. Şekil 4' teki deney akış diyagramında görüldüğü gibi deney 4 bölüm olarak hazırlanmıştır. Birinci bölümde deney, geliştirilen 6 x6 matris bazlı P300 heceletici ve 150 ms uyaranlar arası geçiş süresi ile, ikinci bölümde $4 \times 4$ matris bazlı P300 heceletici ve $150 \mathrm{~ms}$ uyaranlar arası geçiş süresi ile, üçüncü bölümde 6x6 matris bazlı P300 heceletici ve $300 \mathrm{~ms}$ uyaranlar arası geçiş süresi ile ve dördüncü bölümde $4 \times 4$ matris bazlı P300 heceletici ve 300 ms uyaranlar arası geçiş süresi ile gerçekleştirilmiştir. Katılımcılar bölüm sıralarına göre deneye katılmış olup her bir bölüm için farklı günlerde katılım sağlamıştır.

Geliştirilen satır sütun bazlı P300 heceleticide, deneyin birinci ve ikinci bölümünde satır ve sütunlar koyu gri renkte iken, sadece bir satır veya sütun $350 \mathrm{~ms}$ boyunca 1 şı yanmış olup ardından $150 \mathrm{~ms}$ koyu gri renk olup diğer bölgedeki uyaran aktif olmaktadır. Üçüncü ve dördünce bölümde uyaranlara arasındaki geçiş süresi 300 ms olarak ele alınmıştır. Deneyin dört bölümünde de bütün satır ve sütunlar için karışık olarak uyaran birer defa aktif olduğunda bir turu tamamlamış olmaktadır. Şekil 5 'te görüldüğü üzere deneyin birinci ve ikinci bölümünde bir satır veya sütunun flaş yapıp, uyaranlar aras1 bekleme süresi toplamda 500 ms.' dir Böylece bir turu 6 sn'de tamamlanmaktadır. Şekil 6'da ise deneyin üçüncü ve dördüncü bölümünde bir satır veya sütunun flaş yapıp, uyaranlar arası bekleme süresi toplamda 650 ms.'di. Böylece bir turun 7.8 sn sürdüğü gözlemlenmektedir. Hedeflenen karakterin tespiti için 10 defa tur tekrarlanarak 1 dizi tamamlanır. 1 dizideki yapılan turlar ile doğru elde edilen P300 potansiyellerinin, hatalı olanlara karşı oranının artırılması hedeflenmiştir. Böylelikle karakter belirleme süresi deneyin birinci ve ikinci bölümünde $60 \mathrm{sn}$, üçüncü ve dördüncü bölümünde 78 sn olarak gerçekleşmiştir.

4 moddaki P300 heceletici ile yapılan deneylerde eğitim ve test oturumları gerçekleştirilmiştir. 6x6 matris tabanlı P300 heceletisi ile yapılan eğitim oturumlarında. 36 karakterlik eğitim setini içeren kelimeleri deneklerden 2 defa yazdırılması istenerek toplamda 72 karakterlik eğitim seti deneyin birinci ve ikinci bölümü için oluşturulmuştur. $4 \mathrm{x} 4$ matris tabanlı P300 heceletisi ile yapılan eğitim oturumlarında ise 16 karakterlik eğitim setini içeren kelimeleri deneklerden 2 defa yazdırılması istenerek 32 karakterlik eğitim seti deneyin üçüncü ve dördüncü bölümü için oluşturulmuştur. Test oturumunda ise; eğitim setindeki karakterleri içeren "TRUE", "PHONE", "YIELD", "0505", "4923", "ÜÇ”, "İĞNE", "5N1K”, "ÖRÜMCEK”, "EX", “OZON" kelimelerin yazdırılması deneklerden istenmiştir. Böylece 45 karakterlik test verisi elde edilmiştir. 

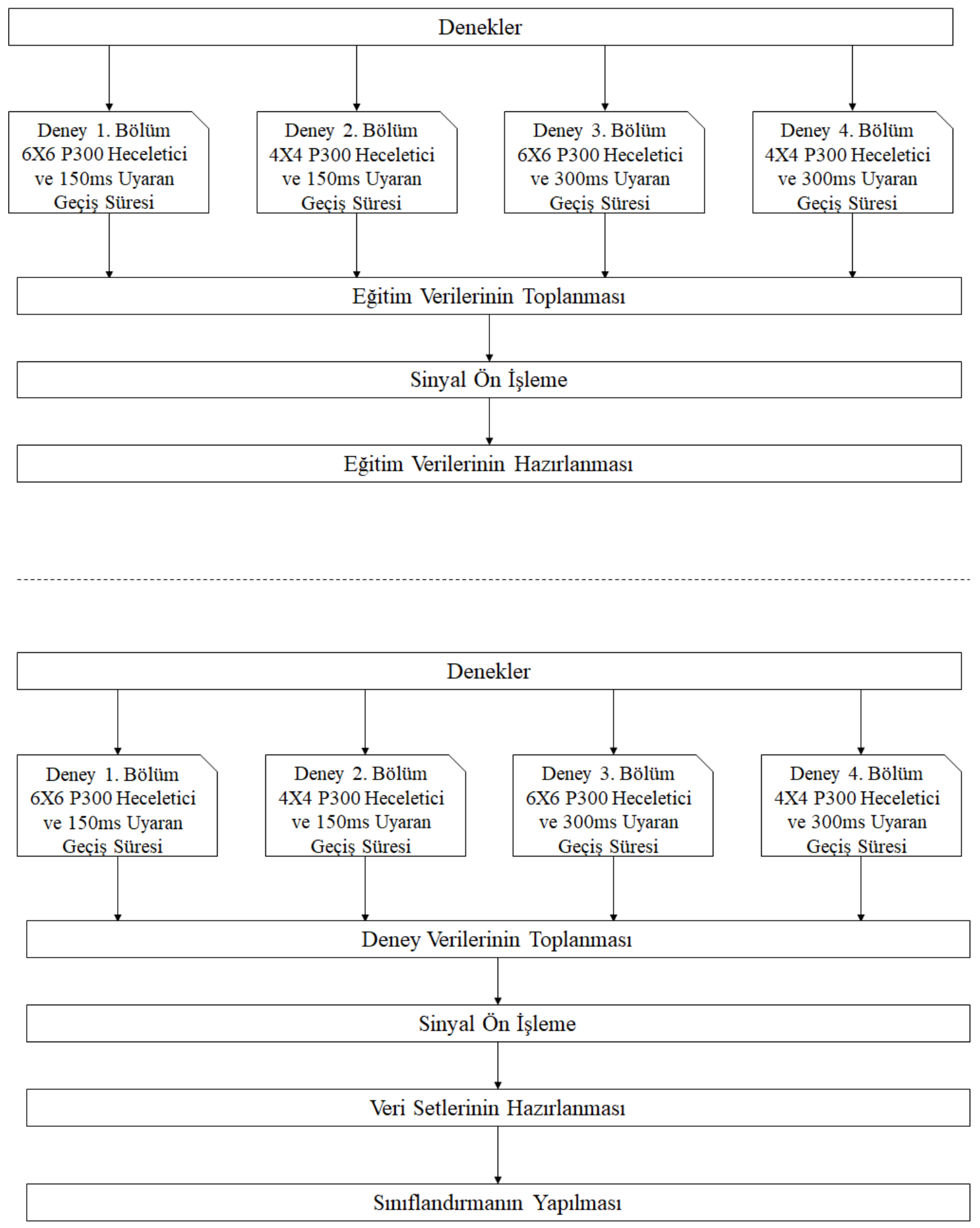

Şekil 4. Deney Bölümleri Akış Diyagramı. 


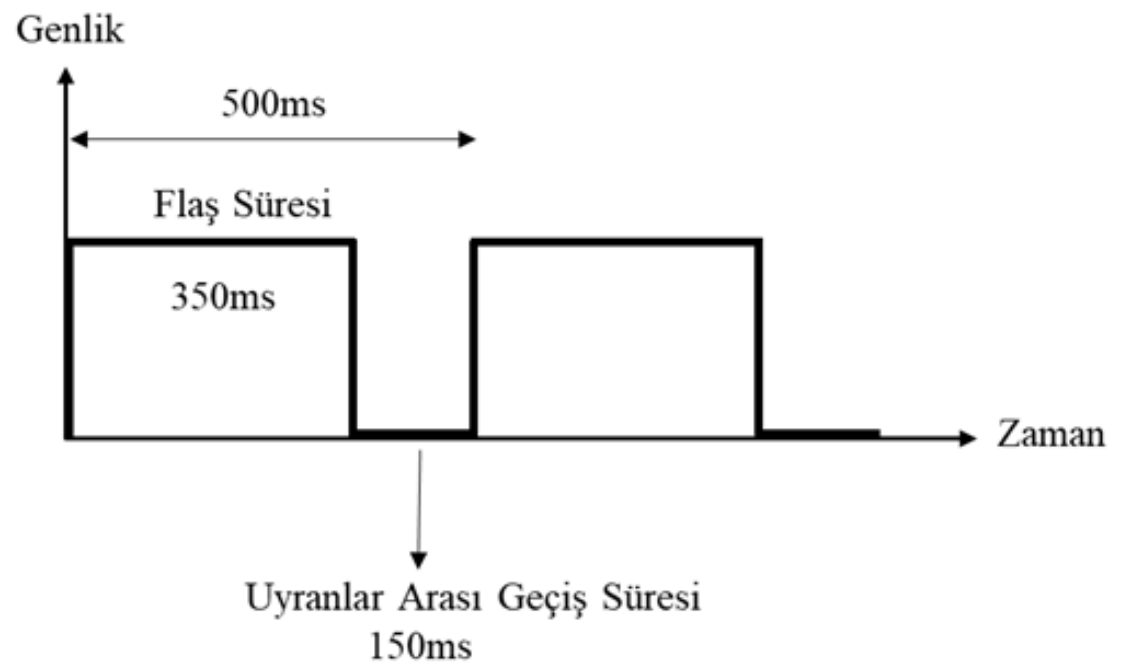

Şekil 5. Deneyin birinci ve ikinci bölümünde, $6 x 6$ ve 4x4 Matris Tabanlı P300 heceleticilerinde Uyaranlar Arası Geçiş Süresi 150ms Olarak Tasarlanmıştır. İki Uyaran Arası Geçiş Süresi Gösterimi.

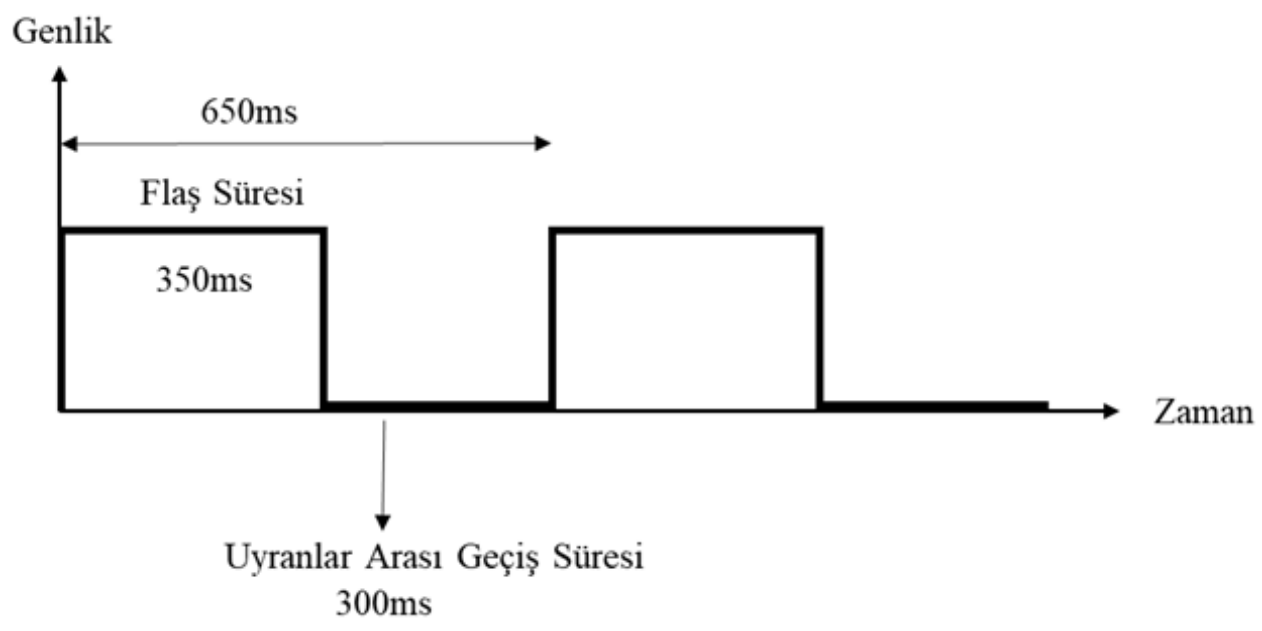

Şekil 6. Deneyin üçüncü ve dördüncü bölümünde, 6x6 ve 4x4 Matris Tabanlı P300 heceleticilerinde Uyaranlar Arası Geçiş Süresi 300ms Olarak Tasarlamıştır. İki Uyaran Arası Geçiş Süresi Gösterimi.

\section{E. EEG SINYAL ANALIZI}

P300 potansiyellerinin araştırılması için C3, C4, Cz, Pz, P7, P8 ve Fz kanallarındaki veriler analiz edilmiştir.

Alınan sinyaller öncelikle ön işlemeye tabi tutulmuştur. Sinyalde oluşabilecek elektrik şebeke gürültüsünü ayıklamak ve beyin aktivitelerinin daha çok olduğu frekans bölgesindeki sinyalleri inceleyebilmek için 5.dereceden Butterworth tipi $1 \mathrm{~Hz}-30 \mathrm{~Hz}$ frekans bandı arasında band geçiren filtre uygulanmıştır. Göz kırpma, göz hareketler, kaslardaki hareketlilik EEG sinyallerinde istenmeyen yüksek genlikli işaretlere sebep olur. Bu aykırı sinyallerin etkilerinin azaltılması için her bir elektrottan alınan kayıtlarda \%80 oranında istatiksel dönüşüm işlemi yapılmıştır. Buna göre, alınan kayıtların tepe ve alt kısımdan \%10'u ortalama en düşük ve en yüksek değere dönüştürülmüştür. Önişlemden geçirilen eğitim kayıtları daha sonrasında 800 ms'lik pencereleme yapılmıştır. Bu işlem bütün elektrotlardan 
alınan kayıtlar için ayrı ayrı uygulanmıştır. $500 \mathrm{~Hz}$ ile örneklenen EEG verisiyle 800 ms'lik parçalardan 400 nokta elde edilmiştir. Alt örnekleme yapılarak 40 noktalı veri kümesi haline getirilmiştir. Aynı zaman dilimindeki 7 adet elektrot kanalından gelen veriler sinyal ortamaları alınıp uç uca eklenmesiyle 280 noktalı veriler oluşturulmuştur. Eğitim verisi sinyal ortalamaları uç uca eklenmiştir. Bu işlem bütün deneklerin 4 farklı moddaki P300 heceleticisinde sınıflandırma işlemi için eğitim veri seti oluşturma amacıyla yapılmıştır.

$\mathrm{Bu}$ çalışmada sınıflandırma için adımsal doğrusal ayrışım analiz (ADAA) metodu kullanılmıştır. Bu metod Fisher's doğrusal ayrışım analiz metodunun genişletilmiş durumu olup EEG verilerinde ve özellikle BBA uygulamalarında başarılı sonuçlar vermektedir [23]. ADAA metodu belirli EEG kanal ve zamana bağlı genlik bilgilerini doğrusal denkleme ekleyerek optimum ayırt edici fonksiyonu bulmaya çalışır. Böylece, eğitim veri seti katsayların ve ayrık fonksiyonun analizi için kullanılmıştır. Bu analizde, elde edilen 400 noktalı veri seti üzerinde sınıflandırma işlemi için uygun noktalar seçilir. Bu nokta seçimleri için tahminlemede kullanılan değişken değeri (p) ayırt edici fonksiyona eklenir. İlk başta hiç bir özelliği bulundurmayan ayırt edici fonksiyon, birbirini takip eden her bir adımda ADAA algoritmas1 $\mathrm{p}<0.1$ değerine sahip olan özelliği ayırt edici fonksiyona ekleyerek giriş verisi olarak değerlendirilmiştir. Devam eden işlemde geriyedönük adım analizi ile önceden belirlenmiş kriterlere uymayan $p>0.15$ değerine sahip özellikleri ortadan kaldırılmıştır. Bu işlem elimine edilecek veya giriş olarak kullanılabilecek özellik kalmayana dek tekrarlanmıştır. Sınıflandırma işlemi sonucunda sinyal, P300 sinyali içeren veya içermeyen sinyal olarak sınıflandırılmıştır.

\section{SONUCLLAR VE TARTIȘMA}

Deney katılımcılarının tümünden alınan sinyaller analiz edilmiştir. P300 heceletisinde yer alan bir karakterin tespiti için, bir dizideki 10 tur boyunca satır ve sütunlarda P300 sinyali içeren sınıflandırma sonuçları 2 farklı matrise kayıt edilir. Sınıflandırma, 10 tur sonunda toplam doğruluk sayısı ile hesaplanmaktadır. Örneğin, denek 4'ün yazdırmasını hedeflediği karakter ("N" karakteri), Tablo 1 ve Tablo 2'de sırasıyla satır ve sütunlardaki P300 sinyali içeren turlarda 1 değerini almıştır. Matrislerde en fazla değeri alan 3. satır ve 2.sütunun kesiştiği karakter olarak deneğin hedeflediği karakter seçilmiştir.

Tablo 1. P300 Sinyali Tespiti Kayıt Matrisi (Satır)

\begin{tabular}{lccccccccccc}
\hline & Tur & Tur & Tur & Tur & Tur & Tur & Tur & Tur & Tur & Tur & Toplam \\
& $\mathbf{2}$ & $\mathbf{3}$ & $\mathbf{4}$ & $\mathbf{5}$ & $\mathbf{6}$ & $\mathbf{7}$ & $\mathbf{8}$ & $\mathbf{9}$ & $\mathbf{1 0}$ & \\
\hline Satır 1 & 0 & 0 & 1 & 0 & 0 & 1 & 0 & 0 & 1 & 0 & 3 \\
\hline Satır 2 & 0 & 0 & 1 & 1 & 1 & 0 & 0 & 1 & 0 & 0 & 4 \\
\hline Satır 3 & 1 & 1 & 0 & 1 & 0 & 0 & 1 & 1 & 1 & 1 & 7 \\
\hline Satır 4 & 1 & 1 & 0 & 0 & 0 & 0 & 0 & 0 & 0 & 1 & 3 \\
\hline Satır 5 & 0 & 0 & 0 & 0 & 1 & 1 & 0 & 0 & 0 & 0 & 2 \\
\hline Satır 6 & 0 & 1 & 1 & 0 & 0 & 0 & 0 & 0 & 0 & 1 & 3
\end{tabular}


Tablo 2. P300 Sinyali Tespiti Kaylt Matrisi (Sütun)

\begin{tabular}{lccccccccccc}
\hline & Tur & Tur & Tur & Tur & Tur & Tur & Tur & Tur & Tur & Tur & Toplam \\
& $\mathbf{1}$ & $\mathbf{2}$ & $\mathbf{3}$ & $\mathbf{4}$ & $\mathbf{5}$ & $\mathbf{6}$ & $\mathbf{7}$ & $\mathbf{8}$ & $\mathbf{9}$ & $\mathbf{1 0}$ & \\
\hline Sütun 1 & 1 & 1 & 1 & 1 & 0 & 1 & 0 & 0 & 0 & 0 & 5 \\
\hline Sütun 2 & 0 & 1 & 1 & 0 & 1 & 1 & 0 & 1 & 1 & 1 & $\mathbf{7}$ \\
\hline Sütun 3 & 1 & 1 & 0 & 1 & 1 & 1 & 0 & 0 & 0 & 0 & 5 \\
\hline Sütun 4 & 1 & 0 & 0 & 0 & 0 & 1 & 1 & 1 & 0 & 0 & 4 \\
\hline Sütun 5 & 0 & 0 & 0 & 0 & 1 & 1 & 0 & 0 & 0 & 1 & 3 \\
\hline Sütun 6 & 0 & 0 & 0 & 0 & 0 & 0 & 1 & 1 & 0 & 0 & 2 \\
\hline
\end{tabular}

Sistemin bütünündeki doğruluk oranı ise; doğru karakter seçimi ADAA algoritmasına göre yüzdesi olarak hesaplanmıştır. 4 farklı heceletici modundaki deneyler sounucunda bütün katılımcıların 45 karakterlik test oturumundaki doğruluk oranı, bir dizideki en yüksek doğruluğa sahip tur sayısı ile hesaplanmıştır. Şekil 7'de deneklerin farklı heceletici modundaki yapısındaki doğruluk oranları değerleri verilmiştir.

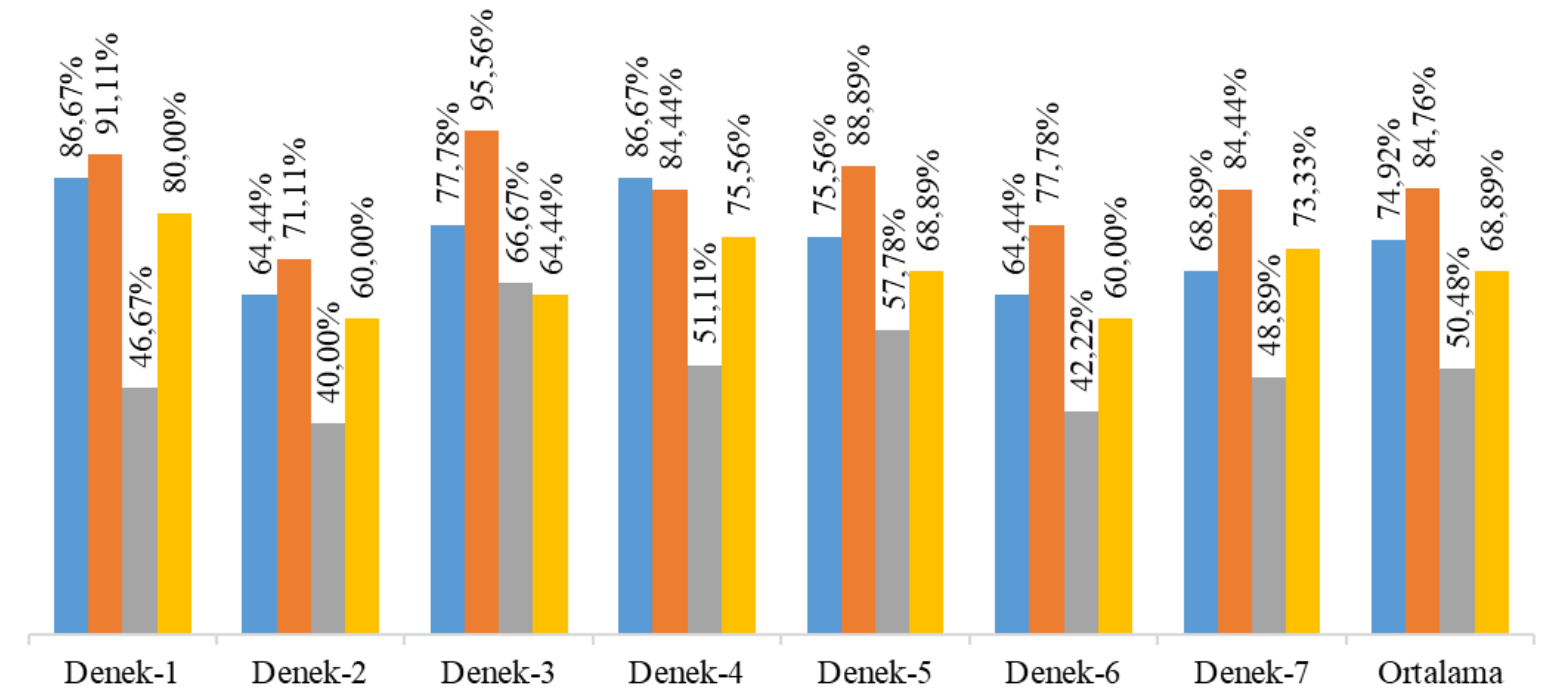

— 6x6 P300 Heceletici 150ms Uyaran Geçiş Süresi — 4x4 P300 Heceletici 150ms Uyaran Geçiş Süresi ఐ6x6 P300 Heceletici 300ms Uyaran Geçiş Süresi $₫$ 4x4 P300 Heceletici 300ms Uyaran Geçiş Süresi

Şekil 7. Farklı Heceletici Modlarında Yapılan Deneylerin Sınıflandırma Doğruluk Oranı

Beyin bilgisayar arayüzü sisteminin performansını etkileyen en önemli faktörlerden birisi olan doğruluk oranı, bu çalışmada 4 farklı değişken yapısındaki satır sütun bazlı bazlı P300 heceletici ile incelenmiştir. Ortalama doğruluk oranı; \%84,76 ile 4x4 P300 heceleticinin 150 ms uyaranlar arası geçiş süresine sahip modda en yüksek olarak tespit edilmiştir. En düşük performans ise; 6x6 P300 heceleticinin $300 \mathrm{~ms}$ uyaranlar arası geçiş süresine sahip modunda \%50,48 olarak gözlenmiştir. 
Ayrıca, yedi denekten 2'si 90\% doğruluk oranının üzerine 4x4 P300 heceleticinin 150 ms uyaranlar arası geçiş süresine sahip modda çıkmıştır.

Deney sonuçları değerlendirildiğinde; satır sütun bazlı P300 heceleticisinde aynı koşullar altında sadece matris boyutu küçüldükçe sınıflandırma doğruluk oranı artmaktadır. Aynı koşullar altında sadece uyaranlar arası geçiş süresi azaltıldıkça, sınıflandırma doğruluk oranı yine artmaktadır.

\section{$\underline{\text { V. TARTISMA }}$}

$\mathrm{Bu}$ çalışmada satır sütun bazlı P300 heceleticisinin uyaran yapısında ve özelliklerinde yapılacak değişikliklerle yüksek doğruluk oranı ile kullanılabilirliği göstermiştir. Doğruluk oranı en yüksek moddaki P300 heceleticisi ile doğruluk oranı en düşük olan mod arasındaki fark \%67,91'dir. Bu değer gösteriyor ki; satır sütun bazlı heceletici yapılarındaki değişikliklerin beyin bilgisayar arayüzü sistemlerindeki performansı direkt olarak etkilemektedir. Deneylerde gözlemlenen bir diğer konu ise P300 heceleticide 6.turdan daha sonrasında doğruluk oranının arttığıdır. Tur sayısının azaltılması karakter tespit hızını artırabilir. Ancak tur sayısının azaltılması doğruluk oranınıda düşürebilir. Bu konu gelecek çalışmalarda araştırılabilir.

$\mathrm{Bu}$ çalı̧̧mada adımsal doğrusal ayrışım analizi kullanılmasına karşın geliştrilen yapay sinir ağları ve derin öğrenme algoritmaları ile ön işleme yapılmadan direkt olarak sınıflandırma yapılabilir. Denenecek farklı sınıflandırma algoritmaları ile sınıflandırma doğruluk oranı daha da artırılabilir.

\section{KAYNAKLAR}

[1] J. R. Wolpaw, N. Birbaumer, D. J. McFarland, G. Pfurtscheller, and T. M. Vaughan, "Brain computer interfaces for communication and control," Clin. Neurophysiol., vol. 113, no. 6, pp. 767791, 2002.

[2] B. He, Z. Liu, "Multimodal functional neuroimaging: Integrating functional MRI and EEG/MEG,” IEEE Rev. Biomed. Eng., vol. 1, pp. 23-40, 2008.

[3] J. d. R. Millán, J. Carmena, "Invasive or noninvasive: Understanding brain-machine interface technology," Eng. Med. Biol. Mag., vol. 29, pp. 16-22, 2010.

[4] Z. Oralhan, M. Tokmakci, "The Effect of Duty Cycle and Brightness Variation of Visual Stimuli on SSVEP in Brain Computer Interface Systems," IETE Journal of Research, vol. 62, no. 6, pp. 795-803, 2016.

[5] N. Birbaumer, A. Kubler, N. Ghanayim, T. Hinterberger, J. Perelmouter, J. Kaiser, I. Iversen, B. Kotchoubey, N. Neumann, and H. Flor, "The thought translation device (TTD) for completely paralyzed patients," IEEE Trans. Rehab. Eng., vol. 8, no. 2, pp. 190-193, 2000.

[6] G. Townsend, J. Shanahan, D. B. Ryan, E. W. Sellers, “A general P300 brain-computer interface presentation paradigm based on performance guided constraints," Neurosci. Lett., vol. 531, 
no. 2, pp. 63-68, 2012.

[7] S. Sutton, M. Braren, J. Zubin, E. R. John, "Evoked-potential correlates of stimulus uncertainty," Science, vol. 150, no. 3700, pp. 1187-1188, 1965.

[8] F. Nijboer, E. W. Sellers, J. Mellinger, M. A. Jordan, T. Matuz, A. Furdea, J. R. Wolpaw, “A P300-based brain-computer interface for people with amyotrophic lateral sclerosis," Clinical neurophysiology, vol. 119, no. 8, pp. 1909-1916, 2008.

[9] S. G. Horovitz, P. Skudlarski, J. C. Gore, "Correlations and dissociations between BOLD signal and P300 amplitude in an auditory oddball task: a parametric approach to combining fMRI and ERP," Magnetic resonance imaging, vol. 20, no. 4, pp. 319-325, 2002.

[10] A. Furdea, S. Halder, D. J. Krusienski, D. Bross, F. Nijboer, N. Birbaumer, A. Kübler, “An auditory oddball (P300) spelling system for brain- computer interfaces," Psychophysiology, vol. 46, no. 3, pp. 617-625, 2009.

[11] S. J. Radlo, C. M. Janelle, D. A. Barba, S.G. Frehlich, "Perceptual decision making for baseball pitch recognition: using P300 latency and amplitude to index attentional processing," Research quarterly for exercise and sport, vol. 72 no. 1, pp. 22-31, 2001.

[12] L. Farwell, E. Donchin, "Talking off the top of your head: Toward a mental prosthesis utilizing event-related brain potentials," Electroencephalogr. Clin. Neurophysiol. vol. 70, no. 6, pp. 510-523, 1988.

[13] C. Guger, S. Daban, E. Sellers, C. Holzner, G. Krausz, R. Carabalona, G. Edlinger, "How many people are able to control a P300-based brain-computer interface (BCI)?," Neuroscience letters, vol. 462, no. 1, pp. 94-98, 2009.

[14] E. W. Sellers, D. J. Krusienski, D. J. McFarland, T. M. Vaughan, J. R. Wolpaw, “A P300 event-related potential brain-computer interface (BCI): the effects of matrix size and inter stimulus interval on performance," Biological psychology, vol. 73, no. 3, pp. 242-252, 2006.

[15] M. Salvaris, F. Sepulveda, "Visual modifications on the P300 speller BCI paradigm," Journal of neural engineering, vol. 6, no. 4, pp. 046011, 2009.

[16] G. Townsend, B. K. LaPallo, C. B. Boulay, D. J. Krusienski, G. E. Frye, C. Hauser, E. W. Sellers, "A novel $\mathrm{P} 300$-based brain-computer interface stimulus presentation paradigm: moving beyond rows and columns," Clinical Neurophysiology, vol. 121, no. 7, pp. 1109-1120, 2010.

[17] P. Meinicke, M. Kaper, F. Hoppe, M. Heumann, H. Ritter "Improving transfer rates in brain computer interfacing: A case study," Neural Information Processing Systems (NIPS), pp. 1107-1114, 2002.

[18] L. Averbuch- Heller, C. Helmchen, A. K. Horn, R. J. Leigh, J. A. Büttner- Ennever, "Slow vertical saccades in motor neuron disease: correlation of structure and function," Annals of Neurology: Official Journal of the American Neurological Association and the Child Neurology Society, vol. 44, no. 4, pp. 641-648, 1998. 
[19] A. J. Suminski, D. C. Tkach, N. G. Hatsopoulos, "Exploiting multiple sensory modalities in brain-machine interfaces," Neural Networks, vol. 22, no. 9, pp. 1224-1234, 2009.

[20] D. S. Klobassa, T. M. Vaughan, P. Brunner, N. E. Schwartz, J. R. Wolpaw, C. Neuper, E. W. Sellers, "Toward a high-throughput auditory P300-based brain-computer interface," Clinical Neurophysiology, vol. 120, no. 7, pp. 1252-1261, 2009.

[21] A. Kübler A. Furdea, S. Halder, E. M. Hammer, F. Nijboer, B. Kotchoubey, "A braincomputer interface controlled auditory event- related potential (P300) spelling system for locked- in patients," Annals of the New York Academy of Sciences, vol. 1157, no. 1, pp. 90-100, 2009.

[22] B. Z. Allison, J. A. Pineda "ERP's evoked by different matrix sizes: implications for a brain computer interface (BCI) system," IEEE Trans. Neural. Syst. Rehab. Eng., vol. 11, no. 2 pp. 110-113, 2003.

[23] U. Hoffmann J. M. Vesin T. Ebrahimi K. Diserens "An efficient P300-based brain-computer interface for disabled subjects," J. Neurosci. Methods, vol. 167, no. 1, pp. 115-125, 2008. 